\title{
LA CIVILIZACIÓN MAYA Y SUS HEREDEROS. UN DEBATE NEGACIONISTA EN LA HISTORIOGRAFÍA MODERNA GUATEMALTECA
}

\author{
Arturo Taracena Arriola \\ UACSHUM, Coordinación de Humanidades, UNAM
}

En estas líneas resumo las ideas que han aparecido en las investigaciones del Centro de Investigaciones Regionales de Mesoamérica (CIRMA) sobre Etnicidad, Estado y nación, 1808-1985, en torno a la tesis del "vacío histórico" o de la "degeneración histórica" que supuestamente se dio entre los grupos indigenas contemporáneos que habitan Guatemala. Esta tesis no sólo ha jugado un papel de primer orden en el proceso de construcción de la identidad nacional guatemalteca, pues incide directamente en la relación existente entre historia y etnicidad, sino que en sí ha condicionado el desenvolvimiento de las relaciones interétnicas en el país.

En su construcción de la idea de nación, el Estado republicano guatemalteco ha combinado asimétricamente políticas de segregación y asimilación, favoreciendo a la primera de estas situaciones, y renovando asi —en cierta manerala praxis del Estado colonial español al haber creado la figura jurídica de las dos repúblicas: la india y la española. Hoy en día, la india y la ladina. Dicha asimetría conllevó una institucionalización de la desigualdad por razones étnicas o, cuando menos, la presencia de prácticas discriminatorias muy acendradas.

Como veremos, la polémica sobre los orígenes de la nacionalidad guatemalteca se da en el marco de un preterismo que sublima el pasado prehistórico monumental, y de un negacionismo que afirma que ya no se reconoce ninguna traza de aquel pasado glorioso en los indigenas contemporáneos — por el olvido de la monumentalidad arquitectónica, de la escritura, de los cálculos astronómicos, del uso calendario solar, etcétera-, pues han sido víctimas de un proceso degenerativo a lo largo de la historia o son producto de otras procedencias no mayas. Tal situación, por tanto, ha hecho necesario recuperarlos antes de que se hundan totalmente o, en el peor de los casos, arrastren para siempre a la nación guatemalteca al pantano del subdesarrollo.

En 1970 los sociólogos Jean-Loup Herbert y Carlos Guzmán Böckler sacaron a la luz en México una obra conjunta titulada Guatemala: una interpretación histórico-social. En ella reaccionaron frente a estas tesis y plantearon que los conceptos aculturación e integración no podían ser introducidos en el estudio de la realidad social guatemalteca sin tomar en cuenta sus raices históricas.

Dichas raices desmentian las supuestas ideas prevalecientes sobre la decadencia, el aislamiento y la gran diversidad de culturas entre los indigenas, como 
corrientemente lo afirmaba la historiografia guatemalteca. Dirigieron sus señalamientos en especial hacia José Antonio Villacorta, quien fungió como ministro de Educación de 1926 a 1944, y cuya impronta historiográfica se mantuvo hasta los años setenta del siglo pasado. Paralelamente, consideraron justo hacer la crítica de las ideologias indigenistas dominantes en la sociedad y el Estado guatemaltecos, que para ellos eran: a) el mestizaje, b) la aculturación, c) la ladinización, y d) la integración social.

Cuestionaban, en consecuencia, el proyecto de construcción nacional a partir de lo ladino, no sólo debido al hecho de la segregación implícita y explícita en él, sino a que, en sí mismo, el ladino no existía como ser colectivo, dotado de un proyecto propio, pues era un intermediario entre el blanco y el indio, por lo que se convertía en no historizable. Con tal afirmación, agregaban otro elemento negacionista al debate, que luego habria de seguir su curso sobre todo des. de la esfera panmaya.

En la historia de estos desencuentros, de estas mutuas negaciones, que empieza a ser muy larga, en esta ocasión quisiera centrarme de forma sucinta en lo que atañe a la construcción historiográfica dominante del negacionismo en torno a la civilización maya y sus herederos.

En el Compendio de la historia de la ciudad de Guatemala (1500-1800). (Aprobada por el Cabildo Eclesiástico en 1808), último proyecto historiográfico colonial aparecido entre 1809-1811, su autor, Domingo Juárros, calificaba a los reinos indigenas que encontraron los españoles como sociedades bien organizadas, ampliamente pobladas, con una estructura jerárquica, en las cuales existía una capa dirigente de origen noble y un amplio sector subalterno que trabajaba a sus órdenes.

El autor afirmaba, asimismo, que sus habitantes no estaban exentos de los problemas que se presentaban en otras civilizaciones: la ambición de poder sobre otros grupos, la conquista de nuevos territorios, las pugnas y divisiones en el interior de cada uno, y las luchas entre ellos. En resumen, no se trataba de grupos dispersos, pacíficos e indefensos, sino de sociedades complejas y sedentarias.

Sin embargo, Juárros no dejaba de subrayar la diferencia abismal que a sus ojos habia entre esos reinos prehispánicos y la sociedad indigena de su época. Así, la existencia de grandes y poderosos señoríos antes de la llegada de los españoles contrastaba con la de los pobres y abandonados miembros de las comunidades contemporáneas. Un discurso que, en sí, no se apartaba de los otros discursos historiográficos hispanoamericanos, los cuales partian de la afirmación de que la conquista y la colonia habian causado en gran medida esa decadencia.

Ahora bien, habría que hacerle un añadido al discurso historiográfico guatemalteco que siguió al de Juárros, tendiente a afirmar que tal decadencia era producto de una dinámica que se venía operando entre las sociedades indigenas guatemaltecas, no desde 1524 , cuando Alvarado inició el proceso de conquista, sino con el desfondamiento de la civilización maya. 
A diferencia de los aztecas y los incas, los mayas habian sucumbido en el siglo $\mathrm{x}$, por lo que sus herederos, k'ichés, k'akchikeles, mames, k'ekchíes y las otras etnias de las tierras altas no merecian necesariamente ser reconocidas como representantes de la antigüedad guatemalteca, por no haber sabido conservar el esplendor de la civilización de sus antepasados. ${ }^{1}$

De esta manera se dio paso a un ejercicio historiográfico que, con el curso de las décadas, fue tendiendo a marcar una desigual recuperación — como parte de un patrimonio histórico común- entre el glorioso pasado maya y el menos glorioso heredado por los reinos indigenas, al punto de que los mayas de las tierras altas y sus herederos terminaron por ser desvinculados culturalmente de los mayas de las tierras bajas, afirmación que cobró brillo a partir de la década de 1960.

El primero en plantear conceptualmente la magnitud de un "colapso" de los reinos prehispánicos previo a la conquista, así como de la tesis del "vacio histórico" entre el siglo x y el xv, fue José Cecilio del Valle, el principal ideólogo del proyecto nacional que los centroamericanos esbozaron cuando fundaron la República Federal en 1823. Del Valle expuso sus ideas sobre la necesidad de que la nueva nación tuviese una geografia e historia patrias en su "Prospecto", aparecido en la Gaceta del Gobierno Supremo de Guatemala del 30 de agosto de 1824. Sin embargo, solamente desarrolló la tesis relativa a la historia en junio de 1830 . cuando desde las páginas del Mensual de la Sociedad Económica de Amigos del Es. tado de Guatemala, ${ }^{2}$ escribió que en "honor de una nación: es interés suyo tener la Historia de su origen, progresos y retrocesos". Y, aunque Guatemala contaba con muchos siglos desde que habia empezado a existir, no tenia en sí historia alguna de aquellos anteriores a su conquista, misma que se contentaba con un "cronicón", refiriéndose de esa manera a la obra de Bernal Díaz del Castillo, con el añadido de que le faltaba aún esa tarea cronistica para los siglos posteriores.

En esta materia, en las obras de los tres cronistas que había tenido el Reino de Guatemala — Antonio de Remesal, Antonio Fuentes y Guzmán y Domingo Juárros-Del Valle consideraba que tan sólo se veía "el espiritu común en los conquistados que hablan de conquista a presencia de sus conquistadores".

Asimismo, él consideraba que, si bien la América habia tenido tres épocas eternamente memorables: la anterior a su conquista, la de los tiempos que estuvo sometida al gobierno de sus conquistadores y la de la gloriosa y justa emancipación, en el caso guatemalteco:

La primera es de tinieblas para nosotros. Ignoramos el grado a que se elevaba la ilustración de los indigenas: no tenemos datos bastantes para medirla: desaparecieron sus archivos y monumentos: fueron destruidos, unos por el tiempo, otros

\footnotetext{
1 Véase Taracena Arriola et ol., Etricidad, Estado y noción en Guotemala, 1808-1944.

2 Del Valle, "Historia". Mensual de la Sociedad Econónica de Amigos del Estado de Gratemalo, 2 : $63-72$
} 
por el sable de los conquistadores: pereció la clase ilustrada y quedó solamente la de los indios ignorantes y desgraciados: el imperio de la conquista los fue embruteciendo más; y a vista del estado en que los vemos parece inverosímil que sus mayores fuesen capaces de escribir una historia digna de este nombre. ${ }^{3}$

De manera que la pieza angular de la desventaja indígena en el discurso nacional empezó a ser su supuesto proceso social de irse "embruteciendo más" desde la desaparición de los mayas, lo cual la conquista española no habia hecho sino reforzar, y el "vacio histórico" lo confirmaba.

Los intelectuales y políticos ligados al Estado conservador y al liberal guatemalteco incorporaron dicha visión derrotista en la historia nacional, por medio de una narrativa y una argumentación que marcaron el imaginario y la evolución política, tanto de los indigenas como de los no indigenas, dejando huellas indelebles hasta el presente en la construcción de la comunidad imaginada nacional. De hecho, ésta ha contribuido a justificar una exclusión en materia de citdadanía y sus campos colaterales (participación política, educación, derechos de propiedad y laborales, etcétera). Más aún, desde el poder, tal exclusión es entendida como una falacia, a partir de la consideración de que los indigenas $-\mathrm{y}$ los pobres en general- nunca lo han sido, puesto que no han ocupado un lugar que se respete en la historia del país.

Entre los republicanos conservadores, fue el arzobispo Francisco de Paula García Peláez quien mejor expresó tal visión en sus Memorias para la historia del antiguo reino de Guatemala, concebidas inicialmente como un proyecto historiográfico oficial durante el gobierno liberal de Mariano Gálvez (1831-1837), pero que sólo fueron publicadas entre 1851 y 1852 , en la coyuntura de la afirmación constitucional del gobierno del general Rafael Carrera.

Su postura frente al balance histórico de las poblaciones prehispánicas era la misma que tenía su predecesor Juárros, y planteaba que se trataba de una sociedad desarrollada que se había enfrentado a los conquistadores, pero había tenido que ser sometida y evangelizada para contener la degeneración y la pereza que venía sufriendo desde antes de la Conquista. El prelado guatemalteco establecía una diferencia abismal entre estas poblaciones prehispánicas - a quienes se refería como "menos estúpidas" - y los indigenas contemporáneos, aunque señalaba estar convencido de que, cambiando el alimento y el abrigo, y dándoles educación, podrían recobrar la "humanidad, hermosura y civilización de los primeros pobladores", es decir, de la civilización maya. ${ }^{4}$

Paradójicamente, consideraba que la colonización española en América habia sido favorable a los indigenas si se comparaba con lo que se hacia en los Estados Unidos, donde era evidente que estaban en vias de desaparición. Sin embargo, advertía que, en el caso de Guatemala, debido a determinados facto-

\footnotetext{
Ibid., p. 64. Las cursivas son mías.

"Garcia Peláez, Memorios poro la historia del antiguo reino de Guatemala, 1943, t. III.
} 
res - como la explotación desmedida a la que estuvieron sujetas las comunidades durante los siglos xv y xvi, y el declive de la producción de cacao- ${ }^{5}$ se había producido una peligrosa disminución de su número poblacional en el siglo xvil. Por tanto, sabiendo la importancia que los indigenas tenían en la producción agrícola y el abastecimiento alimenticio de toda la población guatemalteca, era necesario conocer los errores del pasado para evitarlos en el siglo xix.

Pero no era fácil cambiar las mentalidades en un país cuya economía dependía masivamente de la mano de obra indigena gratuita o semigratuita. Por ejemplo, según un juez, en la década de 1850 algunos indigenas de Escuintla ya se habian creado necesidades de consumo con la propiedad que tenían adquirida por censo enfitéutico, tendiendo a "civilizarse", pero, por otra parte, la mayoría de ellos sólo adquiria los "medios de vivir en su propia condición en la embriaguez y en la vagancia", porque el plátano daba recursos para que no trabajase. Por lo tanto, recomendaba obligarles a "cambiar" de cultivo y a "vestirse de ladinos", con lo cual "mucho podría adelantarse en su regeneración". 6

De esta suerte, los personeros del gobierno conservador comenzaron a resaltar las implicaciones positivas que tenía la asimilación de los ladinos, con base en su capital social y cultural, quienes, ayudados por las medidas agrarias que el Estado dictó en favor de los cultivos perennes como el café, estaban ya en un proceso de integración al mercado interno, a la ciudadanía, a la Nación.

Como lo señaló para el caso guatemalteco el historiador canadiense Steven Palmer (1996) — retomando las ideas de Charles Hale para el caso mexicano-? fueron las obras de Herbert Spencer, aunadas a las de Gustavo Le Bon, las que sedujeron a los intelectuales liberales decimonónicos que tomarían el poder del Estado en 1871 , debido a que éstas contenían una dimensión comparativa etnográfica, que aunada a la teoría de la evolución social de Charles Darwin, permitía argumentar la "degeneración" de indios y mestizos, y también el "carácter moral" de un pueblo o de otro. ${ }^{8}$ Por supuesto, también contaron las ideas de Augusto Comte sobre la subordinación social y la necesidad de mantener el orden para lograr el progreso económico.

E incluso cuando el período que se inició con la Revolución Liberal de junio de 1871 terminó por lanzar a algunos indígenas —especialmente miembros de las elites que controlaban el poder local en las comunidades- a sobrepasar todos los obstáculos "civilizatorios", llegando incluso a ser productores de riqueza, propietarios individuales de la tierra, alfabetos y bilinguies, respetables

\footnotetext{
"Ya sehalada por Antonio Garcia Redondo, Memoria sabre el fomento de las casechas de cocao y de otros romos de agricultura, presentada a la Real Sociedad Económica en 1799.

- Archivo General de Centro América, Ministerio de Gobernación, legajo 28658, expediente 130, citado por Lowell Gudmunson, "Tierras comunales, públicas y privadas en los origenes de la caficultura en Guatemala y Costa Rica", Mesoomerica, 31: 46-47, junio de 1996.

"Hale, The Transformation of Mexicon Liberalism in Late Nineteenth-Century Mexico,1990.

- Véase también Palmer, "Racismo intelectual en Costa Rica y Guatemala". Mesoamérica, 31: 104-105.
} 
comerciantes y ciudadanos (como en el caso de los munícipes de la ciudad de Quetzaltenango y, concretamente, los integrantes de la Sociedad "El Adelanto"), éstos no lograron llegar a ser vistos como parte del imaginario nacional, porque les resultó imposible superar el estigma de la pretendida "degeneración histórica" de su raza, proclamado tanto por el discurso oficial como por el discurso cotidiano del sector no indigena.

El historiador norteamericano Gregory Grandin, ${ }^{9}$ quien investigó a finales del siglo xux las actividades de la municipalidad y la organización mutualista indigenas en Quetzaltenango, señala cuánto pesaban ya en la sociedad guatemalteca las ideas evolucionistas en torno a ese supuesto proceso histórico degenerativo de los indigenas. Frente a ello, los principales quetzaltecos optaron por asumir el papel de promotores de la "raza indigena", con un discurso alternativo emergente, que en términos culturales y políticos buscó rendir cuentas de los cambios socioeconómicos que se estaban operando bajo pleno éxito del régimen liberal. En un Manifesto al presidente de la república, escribian:

El pueblo indígena quetzalteco $|\ldots|$ que ama el progreso $|. .$.$| , a pesar de haber$ atravesado el largo vía crucis del coloniaje y la oscura noche del fanatismo religioso a que nos obligaron los gobiernos teocráticos, hemos podido levantar nuestro espiritu y hacer por medio del arte, de la industria y del comercio, el testimonio más elocuente de que no somos como muchos creen una raza degenerada y abyecta, sin afán por el trabajo y sin gusto por la civilización. ${ }^{10}$

De esa forma, la elite k'iche' quetzalteca desarrollaba un discurso nacionalista, cargado de elementos propios de la ideología liberal del momento, el cual mostraba que si bien podia imaginar un pasado glorioso, exigía sobre todo una reconsideración de la tesis de la "degeneración histórica", con el objetivo de que la sociedad nacional a futuro incluyese la igualdad étnica y crease mecanismos para evitar la obsolescencia cultural.

Sin embargo, para el Estado guatemalteco el proyecto ladino de nación continuaba siendo la linea a seguir en materia de creación de la comunidad imaginada llamada Guatemala, y en su proyección historiográfica no cabía idea alguna que no fuese la de conciliar de forma utópica el pasado prehispánico con el presente, actitud que ha terminado por ser asumida también por buena parte de la intelligentsia y la dirigencia maya actual. ${ }^{11}$

\footnotetext{
${ }^{9}$ Grandin, "Por la regeneración de la raza y el progreso material de la ciudad: la nacionalización de la etnicidad en Quetzaltenango", en Entre comunidod y nación. La historia de Guatemala revisado desde lo local y to regional, pp. 75-96, 1999.

${ }^{10}$ Archivo Histórico de la Gobernación de Quetzaltenango, "La clase indigena de Quetzaltenango pide al presidente de la República ordene se les ponga en posesión de su edificio municipal", caja 1895, citado por Grandin, op. cit., pp. 75-76.

"Una excepción notoria es la del historiador y antropólogo kakchikel Edgar Esquit, véase "Las rutas no ofrecen el pasado y el presente: la recuperación de la historia maya desde el activismo político", en Memorios del mestizaje, 2004.
} 
En efecto, la Revolución Liberal de 1871 constituyó el triunfo histórico del emergente sector cafetalero ladino del occidente del pais y la implantación de su hegemonia sobre los indigenas y el resto de los ladinos, hecho que significó para la elite cafetalera su transformación en clase dominante..$^{12}$ De ahí se derivó la necesidad liberal de movilizar y controlar a la sociedad en su contexto global para beneficio de una clase terrateniente en el seno del desarrollo nacional, ya fuesen sus miembros nacionales o extranjeros, ladinos, criollos o blancos.

Asi se comprende por qué, a pesar de que los objetivos del proyecto eugenésico contemplaban entre sus finalidades la "civilización" y el "mejoramiento de la raza indigena", su meta primordial fue la de "blanquear" al universo no indigena —especialmente el de los ladinos y los criollos_. lo que produjo un consecuente ahondamiento de los estereotipos de origen colonial y el surgimiento de la ideología basada en la bipolaridad indio-ladino. De esta forma se dividió a la población guatemalteca en dos mundos opuestos, al punto que se simplificó la división estadística por origen étnico. Por supuesto, ello no negaba, sino profundizaba, el hecho de que en los discursos de la cotidianidad, la "blancura" era vista - y sigue siéndolo- de diferente forma por blancos (europeos y norteamericanos), criollos, ladinos e indigenas.

A inicios del siglo xx, el principal impulsor de esa visión en la historiografia oficial liberal fue, precisamente, José Antonio Villacorta, quien, imitando a los intelectuales mexicanos, propuso un proyecto historiográfico total desde el Estado, con aplicaciones pedagógicas a nivel de la educación primaria, secundaria y universitaria. También se encontraba inflluido por los hallazgos arqueológicos en territorio guatemalteco de científicos de universidades norteamericanas, en el marco del florecimiento de los congresos internacionales sobre la civilización maya.

En las décadas de 1910 y 1920 los nuevos hallazgos arqueológicos realizados por Edgar Hewett, Sylvanus G. Morley y Giliam Gatwes, entre otros, apoyados por la Escuela Americana de Arqueología de Nuevo México, la Carnegie Institution de Washington y la Universidad de Tulane, además del financiamiento de la United Fruit Company, impactaron el discurso historiográfico guatemalteco dándole aún mayor énfasis a la tesis del desfondamiento civilizatorio que había antecedido la conquista española.

El 14 de junio de 1926 el Diario de Guatemala reseñaba que el historiador Villacorta, ya para entonces ministro de Educación, consideraba a los mayas no como "ancestros", sino como "antecesores" en habitar el territorio guatemalteco. Esta era una civilización que merecía elogios como una de las más grandes de la Humanidad, pero que no tenía continuidad, haciendo inexistente la relación con los indigenas contemporáneos. "Una vasta civilización pasada, que no

12 Taracena Arriola, Invención criolla, sueio fadino, pesadilia indigeno. Los Altos de Guatemala: de region a Estado, 1740-1871, 2000. 
nos ha dejado sino el recuerdo trunco de sus ruinas", repetia el historiador en $1949 .^{13}$

Asimismo, la recuperación nacionalista que Villacorta hizo del Popol Buj o Manuscrito de Chichicastenango y de otras crónicas indigenas, ${ }^{14} \mathrm{y}$ el hecho de que se consolidara el concepto "maya-quiché". ${ }^{15}$ no pudieron superar la lógica del discurso del "vacio histórico", sino que éste más bien se profundizó, con el agravante de que acabó por invisibilizar a otros grupos étnicos contemporáneos.

En esta obra, Villacorta consideraba a los k'ichés con un grado de desarrollo importante y los situaba como una "nación" colindante con los mayas. Una nación de procedencia tolteca, que se había establecido en territorio guatemalteco desde el siglo xı, y que interactuó con pobladores de filiación maya, dando paso a la civilización maya-quiché.

Asi, a la llegada de los españoles, la nación k'iché, si bien ocupaba gran parte de la región occidental de Guatemala, Chiapas y Tabasco, "en los siglos anteriores su influencia se extendía por la parte norte hasta las aguas del golfo mexicano, al este por las riberas del Usumacinta, confinando con los mayas, al sur hasta las playas del Pacifico, y al occidente hasta el istmo de Tehuantepec". 16

Si se toma en cuenta que Villacorta siguió siendo ministro de Educación en la dictadura del general Jorge Ubico, a pesar de denunciar el infortunio de los indigenas ante la conquista española, tal discurso historiográfico terminó por reafirmar al ladino como "elemento de progreso", puesto que el indígena continuaba sometido a un sistema de trabajo forzoso en las fincas cafetaleras o de caña de azúcar, por medio de las habilitaciones y leyes contra la vagancia.

En el fondo estaba la convicción - no sin cierta fatalidad- de que el proceso de mestizaje, si llegaba a darse como un fenómeno total, lo seria en el largo tiempo (la longue durée), no sólo por la tenaz resistencia indigena, y por la dinámica social y estatal de mantener los espacios diferenciados, sino también por la convicción hegemónica de que el papel histórico del indigena estaba en la aportación de mano de obra "barata" al proceso económico vigente. Además, habia que aceptar, con fatalismo, que los indigenas seguirían vinculados a sus tradiciones y comunidades sin la menor lealtad a la Nación y a su Estado, debido a su visión estrecha de comunidad. Por tanto, si tal realidad económicosocial no cambiaba, no había razón de hacer historiográficamente al indigena fuente de la guatemaltequidad.

\footnotetext{
13 J. Antonio Vilocorta. En las ciencias y letros anericanistas, juzgado por sus contemporúneos, 1949.

14 Villacorta y Rodas N., Menuscrito de Chichicostenongo [Popol Buj], estudios sobre los antigues tradiciones del pueblo Quiché, 1927.

15 El concepto mana-quiché cobró fuerza a inicios del siglo $x$, pero realmente se consolidó en la década de 1920, por los esfuerzos del músico Jestis Castillo y de los historiadores josé Antonio Villacorta y Antonio Batres fáuregui. Este último diferenciaba eatre los maya-quichés del siglo xa y los quiché-guatemaltecos del siglo xw. Véase Batres Jáuregui, La Anérica centrol ante sur historia, 1916, pp. 264-26.5.

16 Villacorta y Rodas N., op. cit., p. 5.
} 
Como elemento adicional, al juzgar la herencia mesoamericana, Villacorta afirmaba que la "raza indigena, bastante degenerada" era la de origen mexicano, con sus representantes, los pilpiles, nonoalcas y tlaxcaltecas, ${ }^{17}$ aseveración que también afectaba a los k'ichés, el principal reino que encontraron los españoles en el actual territorio guatemalteco.

Finalmente, la tesis de la "degeneración histórica" anterior a la conquista española fue retomada por Virgilio Rodríguez Beteta en 1950 en el artículo "La caída y desaparición del "primer imperio' maya", donde afirmaba con nostalgia nacionalista:

¿Qué hubiera sido de la historia de Guatemala si el imperio maya de su tierra y de su suelo [...] hubiera conservado en toda su integridad la esencia, potencia y grandeza del Antiguo Imperio a la hora en que llegaron los europeos a América? [... Poblado el norte de Guatemala por el fuerte imperio de los antiguos mayas, quizá la homérica epopeya de los conquistadores, con Hernán Cortés al frente, se hubiera enderezado hacia el Petén ltzá. $Y$ si esas razas peteneras que en los tiempos del Descubrimiento eran sólo jirones de tribus, restos lejanísimos del Viejo Imperio, opusieron una tenaz resistencia a don Martin de Urzúa y a los capitanes que antecedieron en la empresa de sojuzgarlas, qué no hubiera sido si éstos tienen que enfrentarse con el antiguo Mayab. La tenaz y poderosa resistencia del Mayab compacto hubiera quizás trazado derroteros muy distintos a los del vasallaje incondicional en que cayeron las razas indigenas, ya sin unidad ni cohesión de Yucatán y Guatemala. ${ }^{18}$

Tal lamentación histórica estaba contenida también en El libro de Guatemala grande, ${ }^{19}$ que buscaba revalorar la riqueza de El Petén, publicado en 1951, en momentos en que el Estado guatemalteco planeaba una política de distribución de tierra y colonización en el norte del pais, con el objeto de poner fin al aisla. miento político del departamento más extendido de Guatemala, colindante con México.

Consciente del desafío, Rodriguez Beteta apelaba al patriotismo guatemalteco exaltando la grandeza prehispánica maya y la fiereza conquistadora, en aras de potenciar el resurgimiento de aquellas tierras infinitas donde habian quedado las "cenizas" del Antiguo Imperio, sin que por ello se hiciese exaltación alguna de los hombres y mujeres indigenas sobre cuyos brazos habria de descansar tal empresa desarrollista:

Porque de las causas a que haya obedecido la caída y desaparición del antiguo imperio dependerá en buena parte el optimismo o el escepticismo con que nos

\footnotetext{
17 Villacorta, Elementos de Historia patria ajustados al prograna vigente para los alumnos de las EscueIas Complementarios de la República, 1919.

is Rodriguez Beteta, "La caida y desaparición del "primer imperio" maya", Antropología e Historia de Curatemala, II |2|: 55.

${ }^{13}$ Rodriguez Beteta, El Vibro de Guatenala grande. T. I y II.
} 
aboquemos a la idea de resucitar, para el hombre, para la civilización, para la patria y para la humanidad, aquellas tierras inmensas que cubren de cenizas (en todo caso fértiles y fecundas) del Antiguo Imperio. ${ }^{20}$

La vulgarización del pensamiento que tuvo lugar en Del Valle y Rodriguez Beteta, pasando por Villacorta, puede rastrearse con facilidad en las publicaciones guatemaltecas pasadas y presentes. Actualmente, la tesis de la desaparición de los mayas o de la degeneración de sus descendientes es muy común en los discursos académicos, políticos y cotidianos. A nivel de investigación hay arqueólogos, etnohistoriadores, antropólogos, e incluso literatos, que tratan de probarlo, haciendo énfasis en la desconexión de las sociedades prehispánicas y resaltando el "vacio histórico" desde el siglo $\mathrm{x}$ al xvi, asi como el peso determinante de las influencias mexicanas o, aun, el del mestizaje en los grupos indigenas del país, al tiempo que se denuncia la utilización por parte de los intelectuales y lideres mayas actuales de una invención transhistórica para llenar tal vacio, o para encubrir tales procedencias. ${ }^{21}$

También del lado del nuevo movimiento maya se hacen concesiones. Por una parte, en el discurso político se intenta hacer de la historia prehispánica una utopia cerrada en tomo al origen maya, utopia que solamente tiene contacto con el actual proyecto político panmaya y que puede explicarse sin la necesidad de dar luces sobre el "vacío histórico" de los siglos $x$ al xv y sin abordar el terrible legado del período colonial y republicano decimonónico.

Por tal razón, los estudios lingüisticos resultan ser importantes, mientras que los etnohistóricos o arqueológicos no lo son. Se alega que estos últimos son ciencias occidentales, cuando los pueblos mayas tienen sus propios historiadores y memoria — confundiendo memoria con historia-. Es decir, parten de la afirmación de que la investigación histórica violenta las tradiciones.

Sin embargo, tal argumento no tiene consistencia al confirmarse que la mayoria de los estudiantes indigenas - ambos sexos- estudian Derecho o Medicina en diversas universidades del pais, existiendo de antemano el derecho consuetudinario y la medicina tradicional. Sencillamente, el derecho es considerado útil para el presente, mientras que la arqueologia, la etnohistoria y la historia no. El problema radica en que sin ellas dificilmente se combatirá con éxito la base metahistórica sobre la que se construye la ideología racista en Guatemala.

En pocas palabras, no se sigue el ejemplo que dio Carmack hace 15 años con la publicación de Evolución del Reino Quiché. ${ }^{22}$ En 1989, el arqueólogo estadunidense empezó a rebatir directamente la tesis de la degeneración histórica de los

\footnotetext{
as bid., p. 54.

21 Véase, por ejemplo, Gutiérrez Mendoza, Posesiones teóricas de la orqueología guotemalteca, 1996. y Morales, La articulaciỏn de las diferenciás o el sindrome de Maxinón: los discursos literarios y polaticos del debate interítnico en Guatemola, 1998, pp. 217-219 y 332.

2 Carmack, Evohición del reino quiche, 1979.
} 
pueblos indigenas posteriores a la civilización maya. Carmack señalaba que la crítica de Herbert y Guzmán Böckler a los estudiosos guatemaltecos que ignoran el papel de los k'iche's y de las otras etnias en la historia del país, era acertada, puesto que se desconocía deliberadamente que éstas habian podido formar poderosos reinos en el altiplano maya tres siglos o más antes de la conquista española.

Sostenía que eran reinos poseedores de una cultura compleja, que al igual que la española, eran productores de las raices de la cultura nacional guatemalteca. Por tal razón, hacia una invitación a dejar de lado las visiones maniqueas sobre los indigenas, como las referentes a los ladinos, propias de la dimensión ideológica bipolar en que se mueve la realidad social guatemalteca.

Podemos concluir, entonces, que al contrario de otros paises del mundo contemporáneo, donde ante el colapso de grandes civilizaciones ancestrales en determinado período histórico (Grecia, Egipto, Irak, por mencionar tres de ellas) sus descendientes no pudieron mantener el acervo tecnológico, científico y cultural de las mismas, pero han construido su identidad nacional moderna sobre la base de reconocerse como sus descendientes, el proyecto nacional de Guatemala, a pesar de los mestizajes y de las conquistas sufridas, oficial y extraoficialmente $-\mathrm{y}$ en gran medida intelectualmente- persiste en rechazar tal vinculo, victima de una sociedad escindida que produce discursos autodestructivos de corte étnico.

De hecho, continuar y profundizar en el camino trazado por Carmack resulta vital para poder comprender las transformaciones que toda sociedad humana sufre en el tiempo, sin que por ello pierda necesariamente sus origenes e identidad. Es necesario un programa sostenido de estudios etnohistóricos, arqueo. lógicos, históricos, lingüísticos, etcétera —principalmente enfocados a la región del altiplano guatemalteco y chiapaneco- , a fin de poder manejar la realidad que se desprende: la homogeneidad maya no puede ocultar su diversidad. Los procesos reales de mestizaje o de hibridación no implican necesariamente hacer del "mestizaje" el único proyecto de construcción nacional. La unidad de Guatemala solamente puede construirse respetando la diversidad, pero con equidad.

La equidad comienza por no descalificar a priori los fenómenos sociales del "otro", por no tener prejuicios "científicos" en la aceptación de la diversidad de origenes y la existencia de elementos de continuidad en la identidad de culturas que han jugado un papel subalterno en la construcción de los Estados-nación, puesto que en si son dinámicas propias a cualquier construcción histórica de una sociedad humana.

La equidad académica consiste en impulsar su estudio histórico con el rigor de investigación exigido, sin la necesidad de aferrarse en demostrar la existencia de un "vacio histórico", que en sí mismo no puede existir. Es simplemente un "vacío de conocimientos". En toda sociedad humana, el "vacio de conocimientos" del pasado es algo normal, que debe llenarse con investigaciones científicas multidisciplinarias. 


\section{BIBLIOGRAFIA}

\section{Documentos}

Archivo General de Centro América, Ministerio de Gobernación, legajo 28658, exp. 130: Memoria sobre el fomento de las cosechas de cacao y de otros ramos de agricultura presentada a la Real Sociedad Económica en 1799 por Antonio Garcia Redondo.

Archivo Histórico de la Gobernación de Quetzaltenango, caja 1895: "La Clase Indigena de Quetzaltenango pide al presidente de la República ordene se les ponga en posesión de su edificio municipal".

Autores citados

Batres Jáuregui, Antonio

1916 La América central ante su historia. Guatemala: Casa Colorada, Marroquín Hermanos Editores.

Carmack, Robert M.

1979 Evolución del reino quiché. Guatemala: Piedra Santa.

Del Valle, José Cecilio

1830 "Historia", Mensual de la Sociedad Económica de Amigos del Estado de Guatemala, 2: 63-72. Guatemala: Imprenta de la Unión.

Esquit, Edgar

2004 "Las rutas no ofrecen el pasado y el presente: la recuperación de la historia maya desde el activismo político", en Memorias del mestizaje. Cultura política en Centroamerica de 1920 al presente, pp. 167-192, J. L. Gould, Ch. Hale y D. Euraque (eds.). Guatemala: CIRMA/Cholsamaj.

Garcia Peláez, Francisco de Paula

1943 Menorias para la historia del antiguo reino de Guatemala, t. III. Guatemala: T1pografia Nacional.

Grandin, Gregory

1999 "Por la regeneración de la raza y el progreso material de la ciudad: la nacionalización de la etnicidad en Quetzaltenango", en Entre comunidad y nación. La historia de Guatemala revisada desde lo local y lo regional, pp. 75-96, J. Piel y T. Little-Siebold (comps.). Guatemala: CIRMA-CEMCA.

Gudmunson, Lowell

1996 "Tierras comunales, públicas y privadas en los orígenes de la caficultura de Guatemala y Costa Rica", Mesoanérica, 31: 41-56. Antigua, Guatemala: CIRM/N PMS.

Gutiérrez Mendoza, Edgar

1996 Posesiones teóricas de la argueología guatemalteca. Guatemala: IIHAAUSAC. 
Guzmán Böckler, Carlos y Jean-Loup Herbert

1970 Guatemala: una interpretación histórico-social. México: Siglo XXI.

Hale, Charles

1990 The Transformation of Mexican Liberalism in Late Nineteenth-Century Mexico. Princeton: Princeton University Press.

Juárros, Domingo Antonio

1981 Compendio de la historia de la ciudad de Guatemala (1500-1800). Guatemala: Piedra Santa.

Morales, Mario Roberto

1998 La articulación de las diferencias o el sindrome de Maximón: los discursos literarios y politicos del debate interétnico en Guatemala. Guatemala: FLACSO.

Palmer, Steven

1996 "Racismo intelectual en Costa Rica y Guatemala", Mesoamérica, 31: 99-121. Antigua, Guatemala: CIRMAPMS.

Rodriguez Beteta, Virgilio

1950 "La caida y desaparición del 'primer imperio' maya", Antropologia e Historia de Guatemala, II (2): 51-67. Guatemala: Fundación para el Avance de los Estudios Mesoamericanos (FAMSI).

1951 El libro de Guatemala grande. Guatemala: Tipografia Nacional, 2 ts.

Taracena Arriola, Arturo

2000 Invención criolla, sueño ladino, pesadilla indigena. Los Altos de Guatemala: de región a Estado, 1740-187I. Guatemala: CIRMA.

et al.

2003 Etnicidad, Estado y nación en Guatemala, 1808-1944. Guatemala: CIRMA.

Villacorta Calderón, José Antonio

1919 Elementos de historia patria ajustados al programa vigente para los alumnos de las Escuelas Complementarias de la República. Guatemala: Tipografia Sánchez \& DeGuise.

1949 J. Antonio Villacorta en las ciencias y letras americanistas, juzgado por sus contemporáneos. Guatemala: Centro Editorial.

y Flavio Rodas N.

1927 Manuscrito de Chichicastenango [Popol Buj]. Estudios sobre las antiguas tradiciones del pueblo Quiché. Guatemala: Tipografia Nacional. 